\title{
Development of polymer-bound fast-dissolving metformin buccal film with disintegrants
}

\author{
This article was published in the following Dove Press journal: \\ International Journal of Nanomedicine \\ I October 2015 \\ Number of times this article has been viewed
}

\section{Shaikh Ershadul Haque Angappan Sheela}

Materials Chemistry Division, Centre for Nanomaterials, School of Advanced Sciences, VIT University, Vellore, India
Correspondence: Angappan Sheela Materials Chemistry Division, Centre for Nanomaterials, School of Advanced Sciences, VIT University, Vellore 632 0I4, Tamil Nadu, India

Tel +9l 4162202464

Fax +91 4162243092

Email asheela@vit.ac.in
Abstract: Fast-dissolving drug-delivery systems are considered advantageous over the existing conventional oral dosage forms like tablets, capsules, and syrups for being patient friendly. Buccal films are one such system responsible for systemic drug delivery at the desired site of action by avoiding hepatic first-pass metabolism. Metformin hydrochloride (Met), an antidiabetic drug, has poor bioavailability due to its high solubility and low permeability. The purpose of the study reported here was to develop a polymer-bound fast-dissolving buccal film of metformin to exploit these unique properties. In the study, metformin fast-dissolving films were prepared by the solvent-casting method using chitosan, a bioadhesive polymer. Further, starch, sodium starch glycolate, and microcrystalline cellulose were the disintegrants added to different ratios, forming various formulations (F1 to F7). The buccal films were evaluated for various parameters like weight variation, thickness, folding endurance, surface $\mathrm{pH}$, content uniformity, tensile strength, and percentage of elongation. The films were also subjected to in vitro dissolution study, and the disintegration time was found to be less than 30 minutes for all formulations, which was attributed to the effect of disintegrants. Formulation F6 showed $92.2 \%$ drug release within 6 minutes due to the combined effect of sodium starch glycolate and microcrystalline cellulose.

Keywords: chitosan, sodium starch glycolate, microcrystalline cellulose, drug-delivery system, immediate release

\section{Introduction}

Presently, pharmaceutical research is focusing on the development of new drugdelivery systems as the conventional mode of drug administration suffers from several disadvantages. The rate of drug absorption is also dependant on various factors, like the nature of the drug, its formulation, and its interaction in in vivo conditions, which necessitates the development of fast-dissolving systems using polymers for their effective role as drug carriers. This would increase the bioavailability of the drug at the required site of action and bring about immediate pharmacological action. In addition, these systems ensure greater patient compliance, especially in geriatrics and pediatrics. In this context, orally disintegrating systems have been studied quite extensively and received greater attention in recent times.

Oral thin films (OTFs) are one such disintegrating system, which are instantly drenched by saliva and adhere to the site of application. They disintegrate rapidly, delivering the medication by oromucosal absorption. ${ }^{1}$ Several drugs that would otherwise undergo degradation in the gastrointestinal tract have been successfully administered by this route. ${ }^{2-8}$ This suits patients suffering from repeated emesis, dysphagia, etc, who cannot swallow a large quantity of water. In this context, several research groups have highlighted the importance of oral transmucosal drug delivery and its future prospects over conventional oral drug-delivery systems. ${ }^{9-11}$ 
Therefore, the purpose of the study reported here was to develop a polymer (chitosan)-based oral disintegrating systems of metformin in the form of thin films. Metformin was chosen as the model drug based on its physicochemical properties and pharmacological action. The main limitations of metformin toward therapeutic effectiveness - its poor bioavailability $(50 \%-60 \%)$, short biological half-life (5 hours), having the proximal small intestine as its main site of absorption, and the maintenance of adequate plasma levels of the drug ${ }^{12,13}$ - are overcome by this method of systemic drug delivery quite satisfactorily. Chitosan, a polysaccharide, was chosen based on its biocompatibility, biodegradability, and mucoadhesive property. The bioavailability and disintegration properties of OTFs in saliva are increased by adding different ratios of super-disintegrants such as starch, sodium starch glycolate (SSG), and microcrystalline cellulose (MCC). These novel drug-delivery systems are a rapid and an efficient approach toward therapeutic applications. ${ }^{14,15}$

\section{Materials and methods \\ Materials}

Analytical grade metformin and MCC were obtained from Cipla Limited, Mumbai,India. AR-grade low-molecular-weight chitosan with a viscosity of 20-300 cps, starch, and SSG were purchased from Sigma-Aldrich Co (St Louis, MO, USA) and used as received. All other chemicals and reagents used were of analytical grade. The assay of the chosen drug (metformin hydrochloride) was validated and found to be $98.96 \%$ as per Indian pharmacopoeia (IP) 1996 and pre-formulation study was also carried out for the drug. Dissolution medium (pH 6.8) was also prepared as per IP 1996.

\section{Methods}

\section{Preparation of fast-dissolving buccal films}

Different formulations of metformin fast-dissolving films (F1-F7) were prepared from metformin, chitosan, various disintegrants, sucrose, citric acid, and glycerol by the solvent-casting technique (Table 1). Chitosan (204 mg) was dissolved in $1 \%$ acetic acid and stirred until a clear solution formed. To this, a calculated amount of metformin $(500 \mathrm{mg})$, disintegrating agents - sucrose, citric acid, and glycerol - were added and diluted to $20 \mathrm{~mL}$ using doubledistilled water. The solution was stirred continuously to obtain a clear bubble-free viscous solution, transferred into a clean petri dish (area of $13.995 \mathrm{~cm}^{2}$ ), and kept at room temperature for approximately 24 hours. The prepared films were then cut into a size of $2 \times 2 \mathrm{~cm}^{2}$, packed in aluminum foil, and stored in a desiccator.

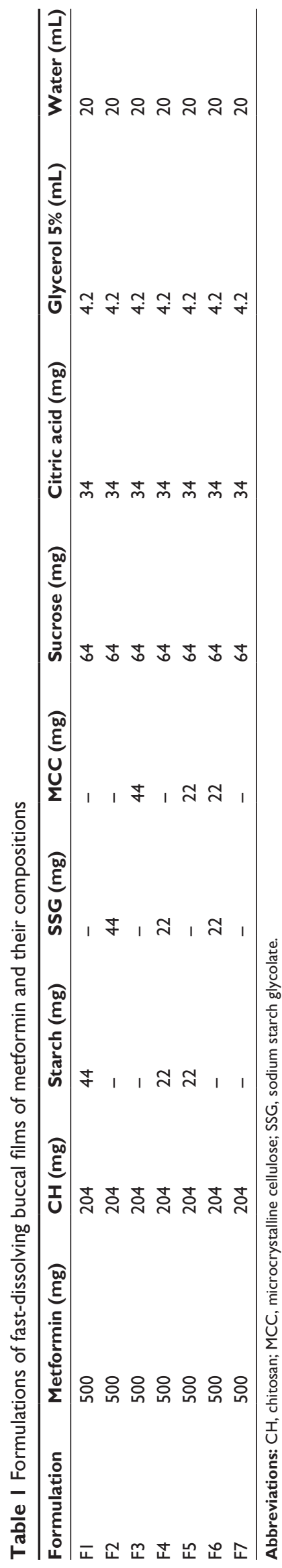




\section{Characterization of buccal films}

Fourier transform infrared spectroscopy

The infrared absorption spectra of OTFs (F1-F7) were analyzed, using a Fourier transform infrared spectrophotometer (IR-Affinity-1, Shimadzu Corporation, Kyoto, Japan).

\section{Mass uniformity and thickness}

Three randomly selected different films from each batch $\left(2 \times 2 \mathrm{~cm}^{2}\right)$ were weighed individually on an electronic balance (AUY220 Analytical Balance, Shimadzu Corporation). The average weight of the films was calculated. The thickness of the films was measured by vernier caliper at three different positions on the film and the average was calculated.

\section{Uniform drug content of the buccal films}

The amount of drug present in the films was determined by dissolving the film in $100 \mathrm{~mL}$ of phosphate buffer (pH 6.8) for 8 hours under occasional shaking. Of this solution, $5 \mathrm{~mL}$ was taken out and diluted to $25 \mathrm{~mL}$, and filtered through a $0.45 \mu \mathrm{m}$ Whatman filter paper. The drug content was then determined by UV spectrophotometer at $232 \mathrm{~nm}$. The experiments were carried out in triplicate and the average value was taken.

\section{Determination of surface $\mathrm{pH}$}

Compatibility of the buccal films was determined by measuring surface $\mathrm{pH}$. The films were allowed to dip in $40 \mathrm{~mL}$ of phosphate buffer ( $\mathrm{pH}$ 6.8) at $37^{\circ} \mathrm{C} \pm 5^{\circ} \mathrm{C}$ for 2 hours. The surface $\mathrm{pH}$ of the buccal films was confirmed with a $\mathrm{pH}$ meter.

\section{Evaluation of physical stability}

\section{Folding endurance}

Folding endurance of the buccal films was determined by repeatedly folding one film ${ }^{16}$ at the same place till it broke or was folded up to 350 times manually, which is considered satisfactory to reveal good film properties. The value of the folding endurance was calculated by counting the number of folds made at the same place without the film breaking.

\section{Tensile strength and percentage elongation studies of buccal films}

The strength of the buccal films was determined by measuring tensile strength (TS) and percentage elongation. A universal testing machine (H5K-S UTM, Tinius Olsen Testing Machine Company, Horsham, PA, USA) was used for the determination of TS by maximum stress applied to the buccal film until it reached the point at which it would break. TS was computed by using the cross-sectional area of the buccal film as per Equation $1 .{ }^{17}$ The average of triplicate readings was taken (Table 2).

$$
\begin{aligned}
& \text { Tensile } \\
& \text { strength }
\end{aligned}=\frac{\text { Force at break }}{\text { Initial cross-sectional area of film }\left(\mathrm{cm}^{2}\right)}
$$

Percentage elongation was determined by measuring the distance obtained by the maximum length just before the breaking point of the film on the scale, as per Equation 2. Percentage elongation can also be useful to find out the elasticity as well as the strength of a film.

$$
\% \text { elongation }=\frac{\text { Increase in length }}{\text { Original length }} \times 100
$$

\section{In vitro dissolution studies}

Drug-release studies of the fast-dissolving buccal films of metformin were carried out by using a single-bucket United States Pharmacopeia type I basket apparatus containing $500 \mathrm{~mL}$ of $\mathrm{pH} 6.8$ phosphate buffer as the dissolution medium maintained at $37^{\circ} \mathrm{C} \pm 0.5^{\circ} \mathrm{C} .{ }^{18,19}$ It was stirred at $100 \mathrm{rpm}$ and $5 \mathrm{~mL}$ samples were withdrawn at 2-minute intervals and replaced with fresh phosphate buffer. Absorbance was measured at $232 \mathrm{~nm}$.

\begin{tabular}{|c|c|c|c|c|c|c|}
\hline Formulation & $\begin{array}{l}\text { Weight } \\
\text { (mg) }\end{array}$ & $\begin{array}{l}\text { Thickness } \\
(\mathrm{mm})( \pm 0.05)\end{array}$ & $\begin{array}{l}\text { Folding endurance } \\
( \pm 5)\end{array}$ & $\begin{array}{l}\text { Surface pH } \\
\text { range }\end{array}$ & $\begin{array}{l}\text { Drug content } \\
( \pm I)\end{array}$ & $\begin{array}{l}\text { Disintegration time } \\
(\mathrm{min})( \pm 2)\end{array}$ \\
\hline$\overline{\mathrm{FI}}$ & $85.92 \pm 0.25$ & 0.188 & 297 & $6-7$ & 97 & 18 \\
\hline F2 & $77.82 \pm 0.68$ & 0.187 & 335 & $6-7$ & 98 & 8 \\
\hline F3 & $85.05 \pm 0.29$ & 0.187 & 290 & $6-7$ & 97 & 11 \\
\hline $\mathrm{F} 4$ & $81.25 \pm 1.33$ & 0.188 & 286 & $6-7$ & 98 & 17 \\
\hline F5 & $76.13 \pm 0.32$ & 0.188 & 210 & $6-7$ & 95 & 19 \\
\hline F6 & $82.58 \pm 0.33$ & 0.182 & 291 & $6-7$ & 95 & 20 \\
\hline F7 & $71.90 \pm 0.28$ & 0.176 & 298 & $6-7$ & 97 & 18 \\
\hline
\end{tabular}

Table 2 Evaluation of fast-dissolving buccal films of metformin

Note: Results are expressed as of mean \pm standard deviation $(n=3)$ 


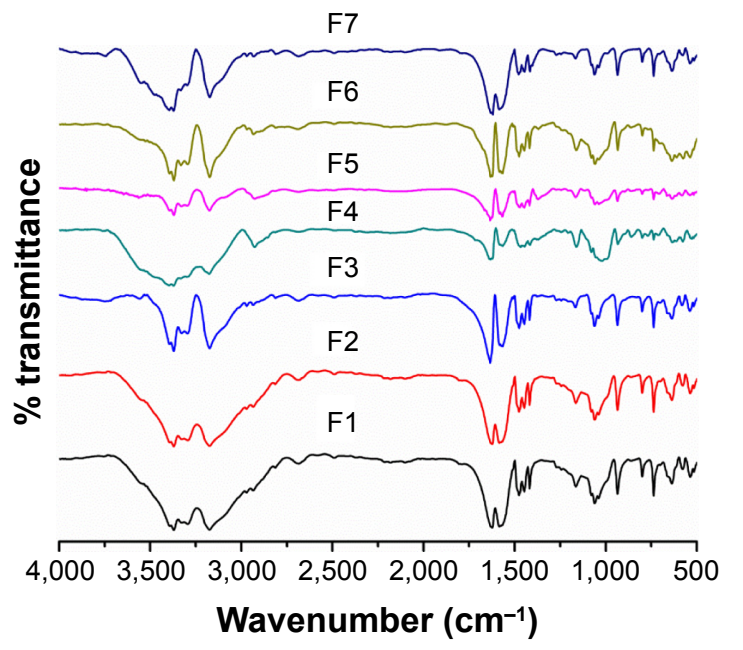

Figure I Fourier transform infrared spectra of drug and polymer with different disintegrants.

The physical parameters, like folding endurance, thickness, TS and \% elongation, provide insight into the stability of the films with regard to their utility in pharmaceutical applications.

\section{Results and discussion}

We obtained desirable compatibility between a drug-polymer and disintegrants with favorable surface properties. Compatibility between a drug-polymer and different disintegrants was compared using Fourier transform infrared spectra. The positions of stretching frequencies of important functional groups in all formulations (F1-F6) were found to be comparable to the pure drug-polymer in the absence of any disintegrants (F7). This indicates that there was no chemical interaction of the drug-polymer with the disintegrants (Figure 1).

In addition, mass uniformity, thickness, folding endurance, surface $\mathrm{pH}, \%$ elongation, and TS values of films were evaluated and were found to be comparable to those of standard limiting values. The surface morphology of the films of different formulations was analyzed using a 100x magnification microscope (RS Microscope System for spectro meter model -PRO-532; PeakSeeker Pro ${ }^{\text {TM }}$-532, Raman Laboratory Systems, Woburn, MA, USA) (Figure 2). The images in Figure 2 show surface modifications based on the disintegrants used. The morphology of the starch-containing films (F1, F4, and F5) was slightly different from the morphology shown by other formulations. F2 and F3 contained SSG and MCC, respectively, as a disintegrant and show more or less similar morphology. F6 had a unique morphology because of the presence of both SSG and MCC and showed greater efficacy.

The prepared films possessed no cracks on their surfaces and were cut into $2 \times 2 \mathrm{~cm}^{2}$ pieces. The various parameters evaluated for all the formulated films are represented in
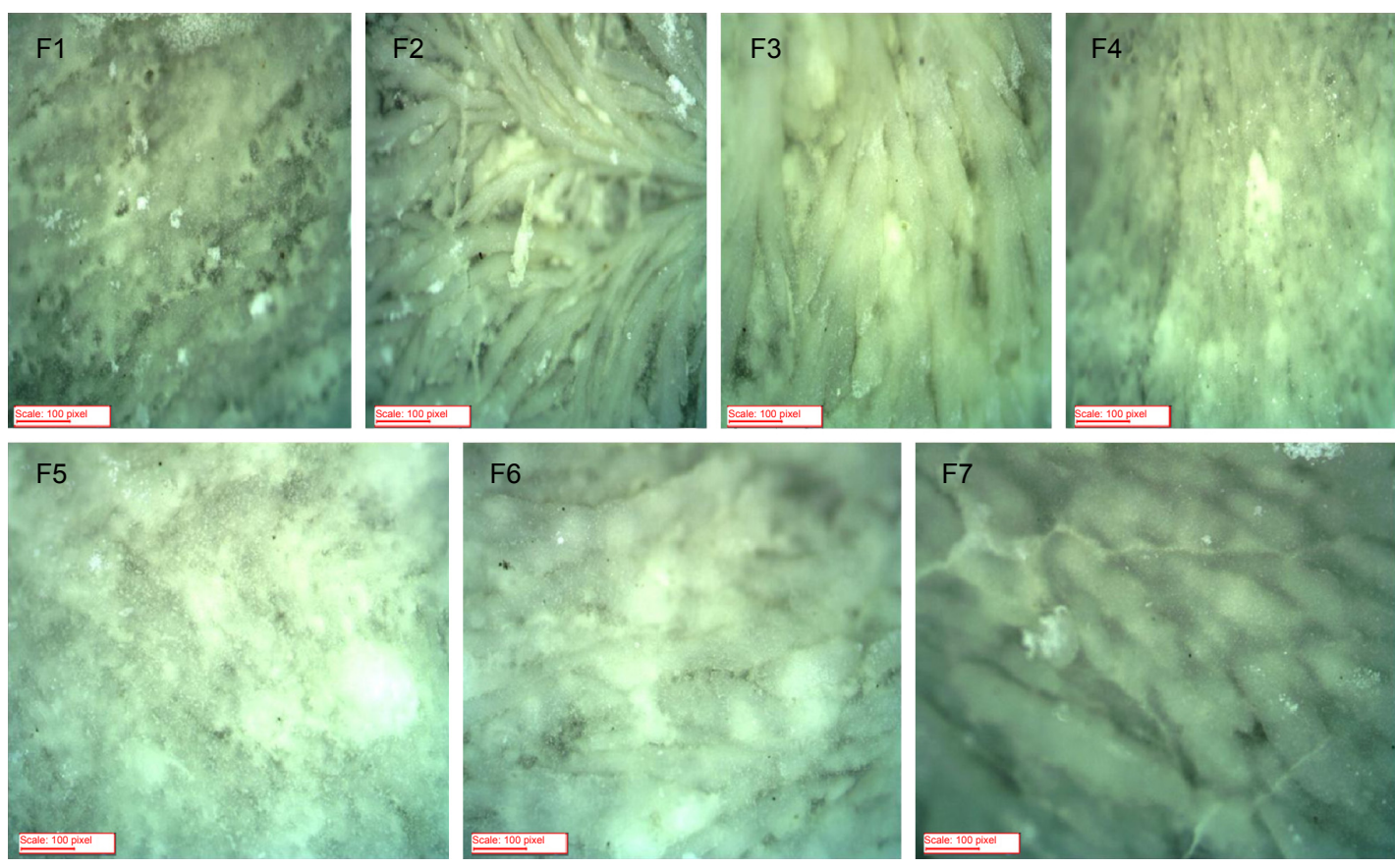

Figure 2 Microscopic images of batches (FI-F7) of metformin fast-dissolving buccal film. 
Table 3 Results of tensile strength and percentage elongation for all films

\begin{tabular}{llllllll}
\hline Formulation & FI & F2 & F3 & F4 & F5 & F6 & F7 \\
\hline Tensile strength $\left(\mathrm{N} / \mathrm{cm}^{2}\right)$ & 0.2452 & 0.2492 & 0.2708 & 0.2502 & 0.1965 & 0.2329 & 0.1884 \\
Percentage elongation & 4.5 & 3.5 & 2.5 & 3.5 & 4.0 & 2.5 & 5.0 \\
\hline
\end{tabular}

Table 2. The weight of films varied from 70 to $85 \mathrm{mg}$ and they exhibited a thickness of approximately $0.1885 \mathrm{~mm}$. We did not observe any substantial increase in thickness with respect to variations in weight attributed to the addition of disintegrants. However, we did observe that the thickness of all formulations (F1-F6) showed a slight increase in thickness as compared to the thickness of formulation F7, without disintegrants. The folding endurance varied between 285 and 335 times, which is considered the sign of good flexibility, except for film F5, containing starch and MCC, which showed lower flexibility. The surface $\mathrm{pH}$ of all the formulations was around neutral ( $\mathrm{pH} \mathrm{6-7)} \mathrm{and} \mathrm{hence} \mathrm{no} \mathrm{irritation}$ would be caused to the buccal cavity. All the formulations contained more than $95 \%$ of the drug, as observed by the drug-content study, which indicated that the formulations were satisfactory for further study.

Mucoadhesive formulations have been designed in various forms, like strips, ${ }^{20}$ patches,${ }^{21}$ disks,${ }^{22}$ films, ${ }^{23}$ etc, and a few potential routes suitable for these dosage forms are via the buccal cavity; sublingually; via the eyes; via the nasal cavity; or via the gastrointestinal, vaginal, or rectal areas. ${ }^{24}$ Among these routes, the buccal mucosa, rich in blood supply, is relatively permeable to systemic circulation and facilitates the rapid absorption of drugs due to their inherent flexibility and elasticity. ${ }^{25,26}$ This made us want to develop fast-dissolving buccal films of metformin targeted to bring about immediate therapeutic action. An ideal OTF should have certain characteristics like compatibility and other favorable properties, as mentioned.

In order to determine the flexibility and elasticity of the buccal films, the TS and \% elongation were calculated and these showed variations based on the disintegrants used in various ratios represented in Table 3. Higher \% elongation and TS were expected for an ideal buccal film. ${ }^{27}$ The TS and $\%$ elongation varied from 0.1884 to $0.2708\left(\mathrm{~N} / \mathrm{cm}^{2}\right)$ and $2.5 \%$ to $5.0 \%$, respectively. Figure 3 represents the comparative TS values. The corresponding \% elongation values are given in Table 3. From this, it can be observed that the TS values increase and \% elongation decreases with the addition of disintegrants in all formulations as compared to the values obtained for formulation F7, without disintegrants. We did not observe any marked differences between formulations F1-F6. ${ }^{28}$

The results of the in vitro cumulative drug release of metformin from all the formulations (F1-F7) are shown in Table 4. The formulations were designed in such a way that the films showed immediate release, thereby having a shorter contact period in the buccal cavity, providing greater comfort to patients. The in vitro dissolution data confirm that all formulations satisfied the requirement of an immediate drug-release profile. F6 showed $92 \%$ of drug release in 6 minutes. All other formulations showed

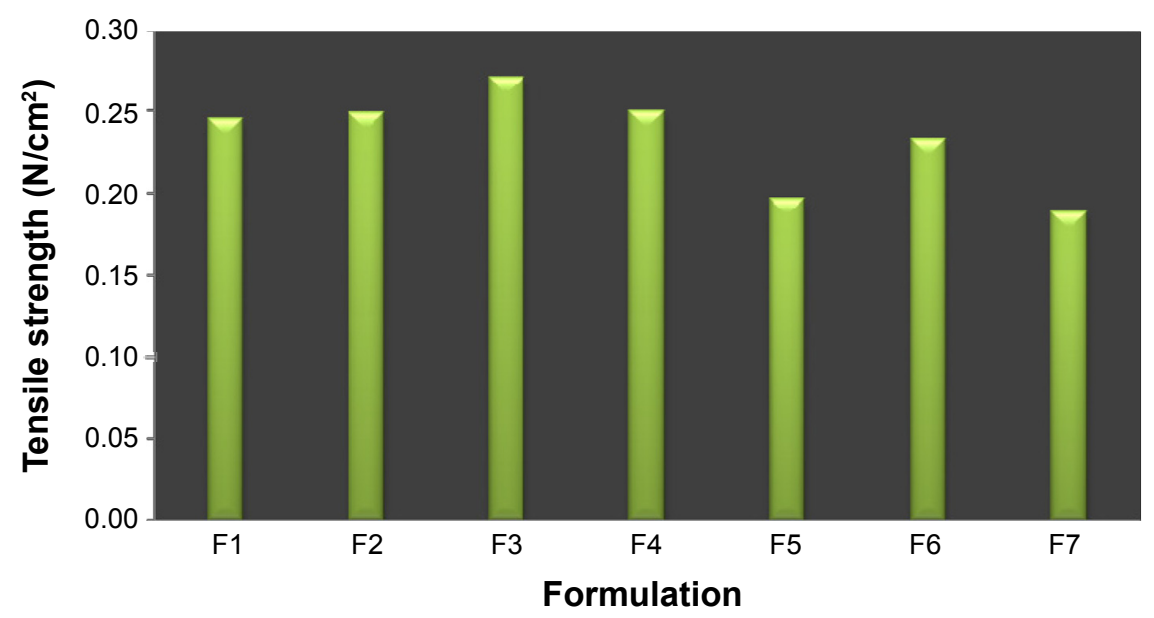

Figure 3 Tensile strength of all buccal films (FI-F7). 
Table 4 In vitro dissolution (\% cumulative release) profile of metformin buccal film

\begin{tabular}{|c|c|c|c|c|c|c|c|}
\hline Formulation & $2 \mathrm{~min}$ & $4 \mathrm{~min}$ & $6 \mathrm{~min}$ & $8 \mathrm{~min}$ & $10 \mathrm{~min}$ & $12 \mathrm{~min}$ & $15 \mathrm{~min}$ \\
\hline $\mathrm{FI}$ & 35.59 & 74.07 & 85.47 & 90.82 & 91.88 & 99.08 & - \\
\hline F2 & 41.93 & 74.07 & 79.76 & 85.57 & 86.76 & 91.88 & 98.96 \\
\hline F3 & 38.32 & 79.78 & 84.04 & 89.02 & 92.99 & - & - \\
\hline $\mathrm{F} 4$ & 34.39 & 70.28 & 75.34 & 79.21 & 82.67 & 87.93 & 96.95 \\
\hline F5 & 10.25 & 39.52 & 68.44 & 80.90 & 87.99 & 97.92 & - \\
\hline F6 & 39.27 & 85.59 & 92.2 & - & - & - & - \\
\hline F7 & 37.75 & 77.05 & 83.07 & 91.78 & 99.00 & - & - \\
\hline
\end{tabular}

more than $90 \%$ release within 10 minutes. The difference in release profile was due to the incorporation of different disintegrants in various ratios. Among all the formulations, formula F6, containing SSG and MCC, was useful for immediate-release drug delivery. Table 4 represents the cumulative $\%$ drug release and a graphical representation is shown in Figure 4.

\section{Conclusion}

The work presented here indicates the great potential of fast-dissolving buccal films containing metformin for systemic delivery that have the added advantage of circumventing hepatic first-pass metabolism. Although various parameters evaluated show optimum values as per the standard limits, the values seem to vary only slightly for formulations F1-F6, as compared to those for formulation F7. The prepared buccal films possessed good mechanical properties as indicated by their TS and \% elongation values. However, these formulations facilitated the immediate release of metformin and also maintained the therapeutic dosage of the drug administered through the buccal route. But, the dissolution test revealed that the most effective immediate release was demonstrated by formulation F6, due to the combined effect of two different disintegrants, $\mathrm{SSG}$ and MCC. It is significant to note that the in vivo bioavailability of a drug can best be predicted based on in vitro dissolution results rather on disintegration tests, as in vivo bioavailability may vary depending upon the nature of the disintegrant or disintegrant combinations used for the specified drug. The types of films discussed here have

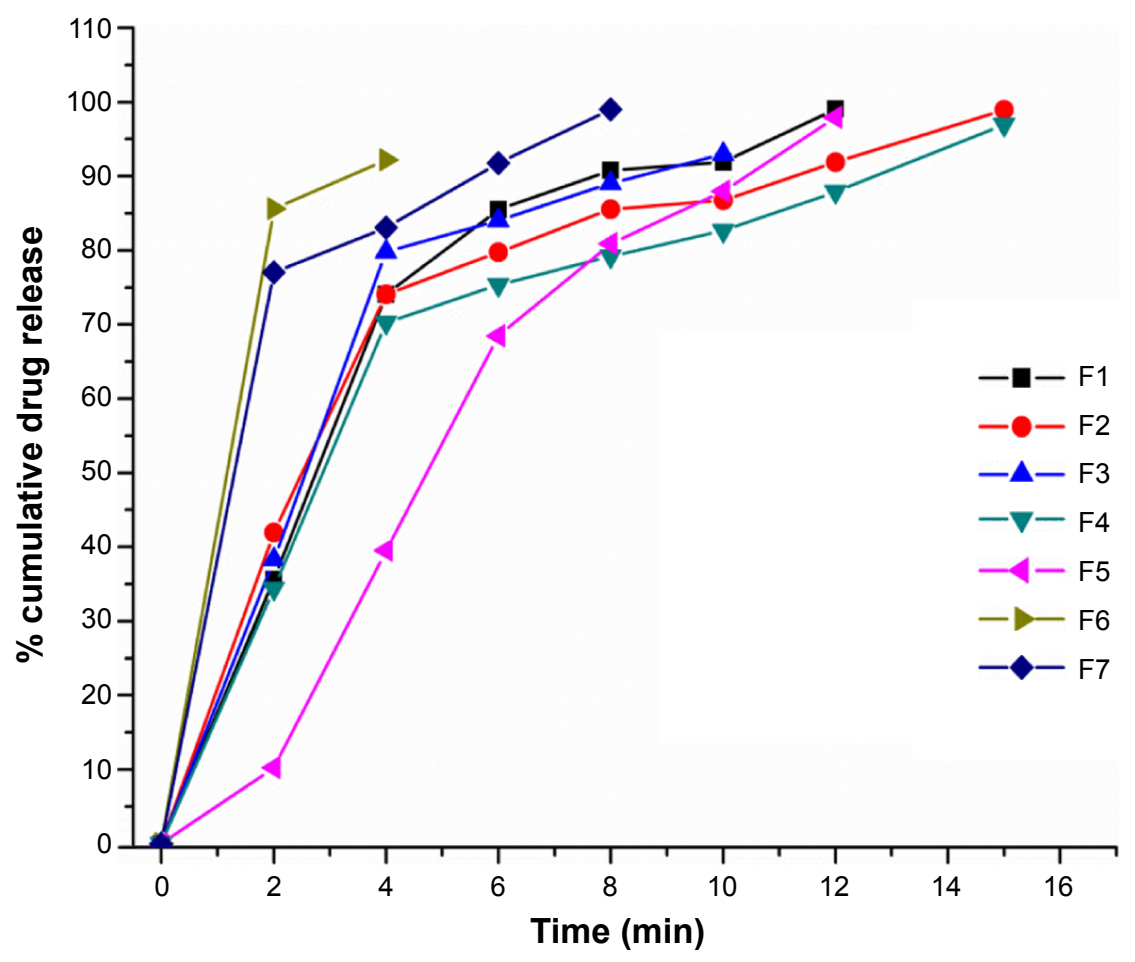

Figure 4 Cumulative drug release of all buccal films (FI-F7). 
greater future prospects for their utility value in emergency situations, provided the issues of stability, durability, and efficacy are taken care of.

\section{Acknowledgments}

The authors would like to thank the management of VIT University, Vellore, India, for its continuous support and facilities provided, as these were instrumental to carrying out the work. Thanks are also due to Johnson \& Johnson for sponsorship. They would also like to extend their gratitude to Dr Sandip Sarkar, School of Social Sciences and Languages, VIT University, for proofreading the manuscript.

\section{Disclosure}

The authors report no conflicts of interest in this work.

\section{References}

1. Barnhart S, Vondrak B. Dissolvable films: dissolvable films for flex product format in drug delivery. Pharmtech.com [serial online]. 2008 April 1: [about 5 p]. http://www.pharmtech.com/ dissolvable-films-dissolvable-films-flexible-product-format-drugdelivery?id=\&pageID=1\&sk=\&date $=$. Accessed March 17, 2015.

2. Anders R, Merkle HP. Evaluation of laminated mucoadhesive patches for buccal drug delivery. Int J Pharm. 1989;49(3):231-240.

3. Chen WG, Hwang GC. Adhesive and in vitro release characteristics of propranolol bioadhesive disc system. Int $J$ Pharm. 1992;82(1-2):61-66.

4. Alur HH, Pather SI, Mitra AK, Johnston TP. Transmucosal sustaineddelivery of chlorpheniramine maleate in rabbits using a novel, natural mucoadhesive gum as an excipient in buccal tablets. Int $J$ Pharm. 1999;188(1):1-10.

5. Guo JH. Bioadhesive polymer buccal patches for buprenorphine controlled delivery formulation in vitro adhesion and release properties. Drug Dev Ind Pharm. 1994;20(18):2809-2821.

6. Ahuja A, Dorga M, Agrawal SP. Development of buccal tablets of diltiazem HCL. Indian J Pharm Sci. 1995;57:26-30.

7. Nagai T, Koshini R. Buccal/gingival drug delivery systems. J Control Release. 1987;6:353-360.

8. Harris D, Robinson JR. Drug delivery via the mucous membrane of the oral cavity. J Pharm Sci. 1992;81(1):1-10.

9. Sattar M, Sayed OM, Lane ME. Oral transmucosal drug delivery - current status and future prospects. Int J Pharm. 2014;471(1-2):498-506.

10. Preis M, Knop K, Breitkreutz J. Mechanical strength test for orodispersible and buccal films. Int J Pharm. 2014;461(1-2):22-29.

11. Mura P, Mennini N, Kosalec I, Furlanetto S, Orlandini S, Jug M. Amidated pectin-based wafers for econazole buccal delivery: Formulation optimization and antimicrobial efficacy estimation. Carbohyd Polym. 2015;121:231-240.
12. Whitehead L, Fell JT, Collett JH, Sharma HL, Smith AM. Floating dosage forms: an in vivo study demonstrating prolonged gastric retention. J Control Release. 1998;55(1):3-12.

13. Basak SC, Rahman J, Ramalingam M. Design and in vitro testing of a floatable gastroretentive tablet of metformin hydrochloride. Pharmazie. 2007;62(2):145-148.

14. Arya A, Chandra A, Sharma V, Pathak K. Fast dissolving oral films: an innovative drug delivery system and dosage form. International Journal of Chem Tech Research. 2010;2(1):576-583.

15. Mashru RC, Sutariya VB, Sankalia MG, Parikh PP. Development and evaluation of fast-dissolving film of salbutamol sulphate. Drug Dev Ind Pharm. 2005;31(1):25-34.

16. Khanna R. Development and evaluation of mucoadhesive buccal dosage form of clotrimazole [master's thesis]. New Delhi: Jamia Hamdard; 1995.

17. Nafee NA, Boraie NA, Ismail FA, Mortada LM. Design and characterization of mucoadhesive buccal patches containing cetylpyridinium chloride. Acta Pharm. 2003;53(3):199-212.

18. Mishra R, Amin A. Formulation development of taste masked rapidly dissolving films of cetirizine hydrochloride. Pharm Tech U S A. 2009;33(2):48-56.

19. Chen MJ, Tirol G, Bass C, Corniello CM, Watson G, Sanchez I. Castable edible pharmaceutical films. Drug Delivery Tec. 2008;8:34-41.

20. Ilango R, Kavimani S, Mullaicharam AR, Jayakar B. In vitro studies on buccal strips of glibenclamide using chitosan. Indian J Pharm Sci. 1997;59(5):232-235.

21. Saisivam S, Asheraff MH, Gerald NS, Jayaprakash S, Nagarajan M. Design and evaluation of diltiazem hydrochloride buccal patches. Indian J Pharm Sci. 2000;62(3):336-338.

22. Krznar DB, Grcic JF, Zorc B, Zovko M. Dissolution of celecoxib from mucoadhesive disks based on polyaspartamide derivatives. Acta Pharm. 2006;56:463-471.

23. Kumar GV, Krishna RV, William GJ, Konde A. Formulation and evaluation of buccal films of salbutamol sulphate. Indian J Pharm Sci. 2005;67:160-164.

24. Ahuja A, Khar RK, Ali J. Mucoadhesive drug delivery systems. Drug Dev Ind Pharm. 1997;23:489-515.

25. Shojaei AH. Buccal mucosa as a route for systemic drug delivery: a review. J Pharm Pharm Sci. 1998;1(1):15-30.

26. Raghuraman S, Velrajan G, Ravi R, Jeyabalan B, Benito D. Design and evaluation of propranolol hydrochloride buccal films. Indian J Pharm Sci. 2002;64(1):32-36.

27. Wong CF, Yuen KH, Peh KK. Formulation and evaluation of controlled release Eudragit buccal patches. Int J Pharm. 1999;178(1): $11-22$.

28. Vishnu YV, Chandrasekhar K, Ramesh G, Rao YM. Development of mucoadhesive patches for buccal administration of carvedilol. Curr Drug Del. 2007;4(1):27-39.
International Journal of Nanomedicine

\section{Publish your work in this journal}

The International Journal of Nanomedicine is an international, peerreviewed journal focusing on the application of nanotechnology in diagnostics, therapeutics, and drug delivery systems throughou the biomedical field. This journal is indexed on PubMed Central, MedLine, CAS, SciSearch ${ }^{\circledR}$, Current Contents ${ }^{\circledR} /$ Clinical Medicine,

\section{Dovepress}

Journal Citation Reports/Science Edition, EMBase, Scopus and the Elsevier Bibliographic databases. The manuscript management system is completely online and includes a very quick and fair peer-review system, which is all easy to use. Visit http://www.dovepress.com/ testimonials.php to read real quotes from published authors. 